children and adults ${ }^{2}$ infections are often mild, with only upper respiratory tract symptoms. Some are reinfections and also frequently mild illnesses. It is difficult to separate the effects of age and immunity in the expression of the disease. ${ }^{3}$ Studies with adult volunteers show that the usual incubation period is three to seven days, ${ }^{4}$ and the outbreak we describe had similar incubation periods. The symptomatic attack rate of about $40 \%$ seems high, but we were unable to study all the patients who were not ill, and possibly there were further asymptomatic infections, which may account for the apparent long incubation period between the first and subsequent cases. The asymptomatic residents who had titres of 20 and 40 may, in fact, have received a boost to their immune system.

Affected patients had illnesses which resembled mild attacks of influenza. Most had received influenza vaccine, and had virological studies not been undertaken the illness might have been ascribed to ineffective vaccines, particularly as the hostel had experienced an outbreak of influenza B infection the year before. In comparison the outbreak of infection with respiratory syncytial virus caused milder illness.

1 The Communicable Diseases Surveillance Centre and the Communicable Diseases (Scotland) Unit. Respiratory syncytial virus activity in the United Kingdom 1979. Fournal of Infection 1980;2:93-7.

${ }^{2}$ Monto AS, Lim SK. The Tecumseh study of respiratory illness. III. Incidence and periodicity of respiratory syncytial virus and Mycoplasma pneumoniae infections. Am $\mathcal{F}$ Epidemiol 1971 ;94:290-301.

${ }^{3}$ Henderson FW, Collier AM, Clyde WA, Denny FW. Respiratory syncytial virus infections, reinfections and immunity. A prospective, longitudinal study in young children. $N$ Engl f Med 1979;300:530-4.

4 Kravetz HM, Knight V, Chanock RM, et al. Respiratory syncytial virus. III. Production of illness and clinical observations in adult volunteers. fAMA 1961 ;176:657-63.

(Accepted 5 September 1980)

Wolstanton, Newcastle-under-Lyme, Staffordshire ST5 8BN DOUGLAS G GARVIE, MB, FRCGP, general practitioner

North Staffordshire Medical Centre, Hartshill, Stoke-on-Trent, Staffordshire ST4 7PX

JOHN GRAY, MRCPATH, DIP BACT, deputy director, public health laboratory

\section{Systemic lupus erythematosus induced by aminoglutethimide}

Aminoglutethimide has been used in the treatment of patients with advanced breast cancer, especially those with painful bone secondaries, as an alternative to adrenalectomy. It suppresses adrenocortical function and inhibits the conversion of androgens to oestrogens peripherally. The two main side effects are lethargy and skin rashes. We report a case of systemic lupus erythematosus induced by aminoglutethimide in a patient with stage IV carcinoma of the breast.

\section{Case report}

A 57-year-old unmarried woman had a mastectomy for carcinoma of the breast (nodes positive) in December 1976. In July 1979 she had severe back pain. Radiographs showed metastatic disease of the dorsal spine. She was given palliative high-energy radiation to the spine, aminoglutethimide 250 $\mathrm{mg}$ four times a day, and cortisone acetate $25 \mathrm{mg}$ twice daily. She was rather drowsy during the first week but had no rashes. On 9 January 1980 she presented with soft-tissue swelling of the fingers, inability to make a fist, and severe aching in the thigh muscles after ordinary exercise. There was no muscle tenderness and no evidence of vasculitis or skin changes. The erythrocyte sedimentation rate was $65 \mathrm{~mm}$ in the first hour, the sheep cell agglutination test for rheumatoid factor was negative, and the antinuclear factor test was positive on two occasions at a titre of 1:500 (homogeneous pattern). DNA binding was $68 \%$ (control $9 \%$ ). Antinuclear antibodies had been monitored from the time of her mastectomy and none had previously been found. Radiographs of the chest and hands showed no abnormality. The most likely diagnosis was thought to be systemic lupus erythematosus despite the fact that the American Rheumatism Association criteria were not fulfilled. There was a polyclonal rise in serum immunoglobulin concentrations, as follows: G $210 \mathrm{IU} / \mathrm{ml}$ (normal range 128-199), A $340 \mathrm{IU} / \mathrm{m}$ (normal range 60-129), M $330 \mathrm{IU} / \mathrm{ml}$ (normal range 97-181). Complement $\mathrm{C} 3$ and $\mathrm{C} 4$ and muscle enzyme concentrations were normal. The urine showed no abnormalities.
The patient's symptoms worsened, her erythrocyte sedimentation rate rose to $94 \mathrm{~mm}$ in the first hour, and on 6 February the aminoglutethimide was discontinued. Within three days her symptoms began to settle, but a week later her erythrocyte sedimentation rate was $103 \mathrm{~mm}$ in 1st hour. No treatment was given. During the next two weeks her erythrocyte sedimentation rate fell to $45 \mathrm{~mm}$ in $1 \mathrm{st}$ hour and she fully recovered. Three months later she was well, although the antinuclear factor remained positive $(1: 100)$ and DNA binding was $40 \%$.

\section{Comment}

Aminoglutethimide appears to be a promising drug in the management of breast carcinoma, but careful monitoring for side effects is essential. Aminoglutethimide is similar in structure to many anticonvulsant drugs (including methoin, phenytoin, primidone, troxidone, and ethosuximide) which are known to produce systemic lupus erythematosus. ${ }^{1}$ It was originally given as an anticonvulsant but was withdrawn from use when pronounced hypothyroidism and adrenocortical insufficiency were noted as side effects. In our patient the test for antinuclear factor was negative before aminoglutethimide was started. Her symptoms responded rapidly to its withdrawal. Therefore the systemic lupus erythematosus may reasonably be ascribed to its administration.

"Spontaneous" systemic lupus erythematosus usually occurs in a younger age group. Wallach ${ }^{2}$ described a lupus-like syndrome in two patients with breast cancer who had been treated with irradiation. In both cases the antinuclear factor showed a speckled pattern. Our patient had received high-energy radiation, but the rapid response to the withdrawal of aminoglutethimide suggests that irradiation was not the causative agent. There have been conflicting reports about the presence of autoantibodies in patients with cancer. Wasserman et al $l^{3}$ confirmed that the incidence of antinuclear antibodies and smoothmuscle antibodies was greater in patients with carcinoma of the breast than in healthy age-matched controls, and Mittra $e t$ al ${ }^{4}$ and Turnbull $\mathrm{et}^{\mathrm{a}} \mathrm{l}^{5}$ found that this incidence was stage-related. Antinuclear antibodies were not present in our patient before she received aminoglutethimide, and therefore presumably were not related to her metastatic disease. We conclude that aminoglutethimide should be added to the list of agents capable of inducing systemic lupus erythematosus.

1 Alarcon-Segovia D. Drug-induced systemic lupus erythematosus and related syndromes. Clin Rheum Dis 1975;1:573-82.

2 Wallach HW. Lupus-like syndrome associated with carcinoma of the breast. Arch Intern Med 1977;137:532-5.

3 Wasserman J, Glas U, Blomgren $H$. Autoantibodies in patients with carcinoma of the breast. Clin Exp Immunol 1975;19:417-22.

- Mittra I, Perrin J, Kumaoka S. Thyroid and other autoantibodies in British and Japanese women: an epidemiological study of breast cancer. Br Med F 1976;i:257-9.

5 Turnbull AR, Turner DTL, Fraser JD, Lloyd RS, Lang J, Wright R. Autoantibodies in early breast cancer: a stage-related phenomenon. $\mathrm{Br}$ f Cancer $1978 ; 38: 461-3$.

(Accepted 1 September 1980)

The General Infirmary at Leeds, and the Rheumatism Research Unit, School of Medicine, Leeds LS2 9PJ

M MCCRAKEN, MB, clinical research assistant

E A BENSON, FRCs, consultant surgeon

P HICKLING, BSC, MRCP, senior registrar

ONE HUNDRED YEARS AGO The metric system makes its way among English and American medical men with some difficulty. Some of the mistakes made in writing about these metric matters are truly comical. The editor of a Western medical journal informs his readers that the nickel five-cent piece is "just a metre in diameter"! This is as good in its way as the story of the New Jersey editor, who, during the Franco-German war, having read in the foreign telegrams that "Bazaine had moved twenty kilometers out of Metz," sat down and wrote the following editorial comment thereupon:- "All friends of humanity in warfare will be delighted to hear that all the kilometers have been removed, and that the innocent people of Metz are no longer endangered by the presence of these devilish engines of warsleeping on a volcano, as it were." Then he went on to describe some experiments made with kilometers in the Crimea, in which one of them exploded and blew a frigate out of the water. (British Medical fournal, 1880.) 